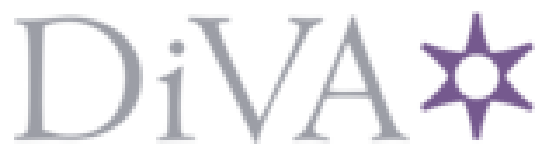

http://www.diva-portal.org

This is the published version of a paper published in .

Citation for the original published paper (version of record):

Ulfsdotter Eriksson, Y., Linde, M. (2014)

"Being" or "Doing" a profession: work as a matter of social identity

The International Journal of Interdisciplinary Cultural Studies, 8(1): 33-43

https://doi.org/10.18848/2327-008X/CGP/vo8io1/53186

Access to the published version may require subscription.

N.B. When citing this work, cite the original published paper.

Permanent link to this version:

http://urn.kb.se/resolve?urn=urn:nbn:se:lnu:diva-97488 


\title{
"Being" or "Doing" a Profession: Work as a Matter of Social Identity
}

\author{
Ylva Ulfsdotter Eriksson, University of Gothenburg, Sweden
}

Malin Linde, University of Gothenburg, Sweden

\begin{abstract}
Occupations are a basic unit for categorizing people: One of the first questions we ask a new acquaintance is, "What do you do?" Occupations are closely related to social identity. Nonetheless, occupational identity has been questioned by researchers who claim that the concept is now outdated. This article explores whether people express occupational identity. Using quantitative data, we analyze how people talk about their occupations in self-presentations. The findings suggest that occupation still defines social identity - especially for incumbents with a defined education, in a high-status occupation or a profession, or in an occupation with a strong cultural framing.
\end{abstract}

Keywords: Social Identity, Occupational Identity, Occupational Prestige

$\mathrm{S}$ cholars have claimed that people identify with their occupation less than they previously did. New employment and working life conditions, such as an increased demand for flexibility and mobility, are assumed to lead to a more unbound relation to occupations and organizations (Casey 1995; Sennett 1998; Isacson and Silvén 2002; Soidre 2004). The assumption is that individuals who frequently change jobs will not be sufficiently socialized to an occupation, preventing it from becoming part of a grounded social identity, and an internalized part of a persona. This implies that the occupation has lost its function as a source of social identity. An occupation, or a profession, is thus only something that we work as.

Others continue to consider occupations to be influencing factors on people's social identities (Ashforth and Mael 1989; Kirpal 2004; Walsh and Gordon 2008). Recent research stresses that work does fulfill personal and social needs and, further, that the workplace develops and maintains social relations (Doherty 2009; Ulfsdotter Eriksson 2012). Work is seen as an important context even for identity matters. An occupation is thus something that we are.

The aim of this article is to analyze whether an individual's occupation still serves as a basis for social identity, and to discuss what factors may influence such identification. The paper approaches questions such as: Do people use occupation as a source of social identity in contemporary society? What influences people to adopt an occupational identity? Do educational level, age, and gender matter?

Theoretically, we depart from social identity theory that highlights how an individual's self-image is affected by the social categories and the context to which he or she belongs (Tajfel and Turner 1979). Since people seek a positive self-image, it may be that a certain occupation's prestige determines whether it constitutes a source of identity. An occupation associated with high prestige may contribute to a positive self-image and therefore be more attractive than an occupation with low prestige (Tajfel and Turner 1979; Ashforth and Mael 1989; Walsh and Gordon 2008). Further, professionals generally have more education and stay in the same occupation for a longer time due to education and training investments. One can assume that such circumstances affect the willingness to adopt an occupational identity. Occupational identity is also fostered by strong associated culture and ideology (Ashforth and Kreiner 1999). A rather obvious hypothesis is therefore that people in high status occupations, in professions, and in occupations with a strong cultural framing have a more stable relation to their occupation, and, thus also express an occupational identity.

Empirically, we approach the issue by using quantitative data from an occupational prestige survey where the respondents were asked to specify how they talk about their own occupation. We focus on presentation and self-reference, that is, whether people say "I am a/an [occupation]," assuming that such phrasing reveals whether or not the occupation is part of an individual's social identity.

The paper is organized as follows: First, we recapitulate social identity theory and how it contributes to an understanding of occupational identity. The next section discusses identification influences and obstacles. Thereafter, we present the study's data, analytical methods and the empirical results. Finally, we close the discussion with some concluding remarks.

\section{Occupation as a Social Identity}

Social identity theory focuses on how people understand themselves in terms of social categorization, but also on what leads to a certain self-categorization (Tajfel and Turner 1979; Ashfort and Mael 1989; Ellemers et al. 2003; Alvesson et al. 2008). The theory, as developed by Tajfel and Turner (1979), focuses on three interrelated processes. First, social categorization captures that people perceive and classify themselves into a wide range of different categories based on, for instance, gender, nationality, age, ethnicity, social class - and occupation. Walsh and Gordon (2008) argued that it is more likely for an individual to adopt a membership in a group when 
it is distinct and associated with high prestige. Second, by comparing groups on relevant dimensions people assert different values; they "assess the relative worth of groups as well as individuals" (Ellemers et al. 2003: 6). The comparison and assignment of values to occupations is well researched in occupational prestige studies (Treiman 1977; Nakao and Treas 1994; Ulfsdotter Eriksson 2006) and the effects of occupations' relative prestige for individual incumbents have also been acknowledged, especially for those working in low-status occupations (Ashforth and Kreiner 1999; Ulfsdotter Eriksson and Flisbäck 2011). Third, people actively relate to their different social settings - working life and occupational belonging being examples - and their identity is influenced and implicated by their social situation. This refers to self-identification due to social circumstances rather than the individuals' inner sense of a self, which is more of a psychological question.

The conceptualization of a group captures that it consists of a collective of individuals who share a common self-definition (Tajfel and Turner 1979). Moreover, social categorizations bring order in a complex environment and provide the individual with cognitive tools (Ashforth and Mael 1989). Nonetheless, by classifying ourselves, we also express belongingness to various "human aggregates" as we consider ourselves as part of an actual and/or a symbolic group (Ashforth and Mael 1989: 21). Self-categorization serves as a "system of orientation for self-reference" (Tajfel and Turner 1979: 40). The question "Who are you?" leads to answers that in various ways denotes the social belonging, or self-reference, expressed in answers such as "I am a woman," "I am Norwegian," or "I am a teacher."

An occupation is a relevant social category delineated with a specific title, defined and clarified by its placement in the social division of labor and the tasks solved, but also by the typical individual filling the position (Krause 1971). Occupational titles are like "tags" (Hughes 1971/2008: 338). They act as signatures of who we are and descriptions of what we do. "What do you do?" is one of the most common questions when we meet new acquaintances (Phelan and Kinsella 2009). In social settings, people are defined by what they do, and their occupation says a lot about their knowledge, educational level, and skills. Against the background of earlier experiences, and knowledge about a person's specific occupation, we can make more or less qualified guesses of who we have in front of us.

Occupation can be defined in several ways, emphasizing the division of labor (Weber 1978), employment relations (Hansen 2001), or, as in Richard Hall's (1969: 5-6) definition, "the social role performed by adult members of society that directly and/or indirectly yields social and financial consequences and that constitutes a major focus in the life of an adult". Hughes (1971/2008: 339) claimed that an individual's occupation is nearly as important and irreversible as a spouse. Therefore, the occupation is regarded as a part of the social identity.

\section{Influences for Adopting an Occupational Identity}

Categorization is a relational phenomenon - identification, recognition, and evaluation by individuals within a certain group and by people outside the group. The social comparison leads the individual to strive for positively valued groups and avoid negatively valued ones (Tajfel and Turner 1979; cf. Ashforth and Mael 1989; Ashforth and Kreiner 1999; Walsh and Gordon 2008).

In the case of occupations, they are often evaluated in terms of high and low prestige, based on factors such as importance, power, skill demands, etc. (Treiman 1977; Ulfsdotter Eriksson 2006). High prestige and reputation contribute to a positive recognition (Ashforth and Mael 1989; Walsh and Gordon 2008). This implies that it would be easier to embrace an occupation ascribed high prestige as part of a social identity since it can therefore be a source of positive identification. Partaking of the occupations' winning qualities is expected to increase the holder's self-esteem. Thus, people employed in occupations that lack such qualities, or in occupations with a negative connotation, may distance themselves more from the occupation.

Hughes (1971/2008: 229) stated that when people introduce themselves to each other, they choose the best available title as they know that the mere title affects the image that others create. This is due to the centrality and importance the occupation has for the social identity. Walsh and Gordon (2008) claim that an individual, in shaping a positively valued work identity, consciously chooses between the organization and the occupation depending on prestige. If the occupation is conducted in a less-prestigious organization, the individual chooses to give prominence to the occupation and vice versa (or both when prestige is equally valued).

Another aspect that may influence occupational identity adoption is socialization. Individuals are subject to socialization in many different social settings. In early childhood, we incorporate our parents' attitudes toward working life and we sometimes even inherit their occupations (Patmalnieks 2011; cf. Willis 1977). This captures a specific form of socialization that also may affect the willingness to adopt an occupational identity, and concerns especially occupations such as farmers and fishery workers to a high degree. Not only do the children in these families grow up in a work-life setting, the means of production are often inherited as well. An informed socialization, including recognition of a specific occupational identity, ensures family heritage.

Another socialization area is school and education. Becker and Carper (1956) studied how graduate students develop occupation identification. In education, the students develop "attachment to occupational title, task 
commitment, and commitment to particular work organizations and/or positions in them" (Becker and Carper 1956: 296). Socialization and learning are interrelated (Casey 1995; Kirpal 2004). Occupations that require a lot of education equip students with a specific understanding of future work, but also with an understanding of the occupation's particular culture and ideology (Hughes 1971/2008).

Some occupations, especially those with minor educational demands, are mainly learned through practice and performance in an everyday setting and by socialization. Even for professional occupations, which demand greater formal education, a great deal of socialization takes place at the workplace (Kirpal 2004). In performing specific tasks in combination with belongingness to a specific work group, the individual internalizes norms, values, standards, etc. Performing a task, regardless of its complexity, may thus generate a positive occupational identification.

As already mentioned, occupational prestige affects the willingness to adopt a positive identity (Walsh and Gordon 2008). However, recent research shows that incumbents in low-status occupations also identify with their occupation (Ulfsdotter Eriksson and Flisbäck 2011). A positive occupational identification was expressed by those who recognized similarities between necessary traits in performing the occupation and their own personal traits (cf. Katz and Kahn 1978; Kirpal 2004). Some of the interviewees in the study used the occupation's title as an expression of pride. Among waste collectors, a low-status occupation and highly associated with dirty work (Hughes. 1971/2008), the incumbents utilized a defense mechanism in turning the negative distinction into a positive one. This is in line with Ashforth and Kreiner (1999), who stated that a strong occupational culture may enable the incumbent to reinterpret "dirt" into pride - a strong culture with a valuation that extends to a positive occupational identification. Some of the interviewees in the study acknowledged that saying "I am" in self-presentations is typical of those working in high-status professions since a "professional" (for example, a lawyer or physician) to a higher degree is seen as something that you actually always are (cf. Elliott 1972). The differences in prestige was thus recognized by them, and to express "I am" in a selfpresentation was regarded snobby and posh. Those applying a more distanced approach to the occupation used wordings like "I work as" or "I work at".

\section{Data and Method}

The following analyses are based on data from a postal survey sent in 2002 to a random sample of the Swedish population aged 16-74. The sample was stratified by age with the largest group being those aged 16-24. The survey was distributed by Statistics Sweden to 3,032 respondents, and the response rate was 61 percent. The analysis in this paper is based on those who also filled in their current occupation. Due to internal non-responses on the question of current occupation, the sample in this paper thus comprises 1,071 respondents. Some results from the minor sample are hence compared to the total response.

In the survey, the respondents were asked to consider the question of self-presentation when answering the question: What do you say when you talk about your occupation? The response alternatives were a) I AM (for instance, a carpenter), b) I WORK AS (for instance, a carpenter), and c) I say something else ("another way"). As Table 1 shows, 43 percent of the respondents use "I am" when talking about their occupation. However, most of them use "I work as," whereas "another way" was the least frequent.

Table 1: Self-presentations in the sample in relation to social class (frequencies, percent)

\begin{tabular}{|l|c|c|c|}
\hline & "I am" & "I work as" or & $(n)$ \\
\hline Working class & 35 & 65 & 616 \\
\hline Farming family & 59 & 41 & 166 \\
\hline Lower middle class & 44 & 56 & 349 \\
\hline Upper middle class & 55 & 45 & 232 \\
\hline Self-employed & 20 & 80 & 45 \\
\hline Analyzed sample & 43 & 58 & 1,071 \\
\hline Total sample & 41 & 59 & 1,408 \\
\hline
\end{tabular}

Comments: Class is a measure of subjective social class where the respondents themselves state to which category they believe they belong. 
In the analyses, we addressed a single focal relationship between the occupation and the phrase "I am" (Aneshensel 2002). Using "I am" when talking about work is interpreted as revealing an occupation-based social identity (Ashforth and Mael 1989; Ulfsdotter Eriksson and Flisbäck 2011). We focus on the probability that the variables are empirically related. Thus, the phrase "I am" is analyzed as a dependent variable and is assumed to reveal the individual's willingness to adopt the occupation as a source of social identity.

The data were analyzed multivariate and we used logistic regression (Edling and Hedström 2003: 173). For the benefit of the analysis, the variable "self-presentations" were coded into a two-option alternative: The response alternatives "I work as" and "another way" were pooled and analyzed in comparison with the phrase "I am." We therefore interpret the odds for respondents identifying with their occupation, "I am" being the dependent variable to be explained. The analysis was conducted in three steps (models), and included four independent variables that can either be alternative explanations or specify the focal relation between occupation and social identity (Aneshensel 2002).

a) Occupation: The purpose of the focal relationship is to find the primary independent variable (Aneshensel 2002), in this case the occupation. The individual occupation has been identified and coded in accordance with the International Standard Classification of Occupations (ISCO-88/SSYK 96). The respondents $(1,071)$ filled in their current occupation, and then we translated their answers in accordance with ISCO-88 categories and major groups. In the final analysis, we used the nine major groups (military occupations excluded). Table 2 presents how the respondents were distributed in the major groups. The table shows that the sample generally matches how the Swedish labor force was distributed to the nine major groups in 2005 (SCB 2005). The sample has a slightly higher representation from groups 4, 5, and 6, and a somewhat lower representation from groups 8 and 9.

b) Educational level: Education may influence the willingness to adopt an occupational identity due to socialization. This is particularly relevant for those who have a vocational training and have spent training time with actual occupational incumbents, as well as for individuals with a higher education who have spent a long time in educational training and hence may have adopted an associated culture and ideology (Becker and Carper 1956). Education is thus an independent variable that might influence occupational identity. The variable consists of five levels: elementary school (reference category) consists of 205 respondents; vocational school, two years of high school (222 respondents); three or more years of high school (291 respondents); less than three years of university (141 respondents); and more than three years of university (212 respondents).

Table 2: The distribution of respondents and practitioners in the Swedish population in the Major occupational groups (percent)

\begin{tabular}{|l|c|c|}
\hline & Respondents & Sweden 2005 \\
\hline Legislators, senior officials, managers & 4.7 & 5 \\
\hline Professionals & 16.9 & 17 \\
\hline Technicians and associate professionals & 18.8 & 9 \\
\hline Clerks & 11.6 & 19 \\
\hline Service, shop, market sales workers & 23.8 & 1 \\
\hline Skilled agricultural and fishery workers & 3.1 & 9 \\
\hline Craft and related trades workers & 8.7 & 10 \\
\hline Plant and machine operators & 8.7 & 6 \\
\hline Elementary occupations & 4.9 & \\
\hline
\end{tabular}

Source(s): data on the Swedish labor force 2005 adapted from Statistic Sweden (SCB 2005).

c) Gender (women as reference category): Gender is an independent variable that may influence the willingness to adopt an occupational identity. It is relevant to include due to the gender-segregated labor market and the fact that men and women may have different working life experiences, which could affect occupational identification. There were 567 women and 504 men.

d) Age: Since occupational identity is dynamic, it may change through life (Kirpal 2004). For a young person, it might be that other aspects of life are more important for social identity, such as being a supporter of a specific football team or a fan of a certain type of music. For an older person, the occupation generally absorbs a larger portion of the waking hours, making age an important variable to control for. A higher age would then increase the odds of identifying with the profession and therefore saying, "I am." Age is a continuous variable between 16 and 75 years. 


\section{I am!}

In the following, we present the multivariate analyses showing the effects from the independent variables on the odds of saying "I am" when presenting oneself. First, though, we introduce the three different phrases' frequencies used by respondents from the nine different occupational groups.

Table 3: The proportion of individuals in each occupational group who responded "I am" and "I work as"/“another way" (percent)

\begin{tabular}{|l|c|c|c|}
\hline & "I am" & "I work as" & $(n)$ \\
\hline Legislators, senior officials, managers & 44 & 56 & 170 \\
\hline Professionals & 56 & 44 & 50 \\
\hline Technicians and associate & 51 & 49 & 201 \\
\hline Clerks & 32 & 68 & 124 \\
\hline Service, shop, market sales workers & 35 & 65 & 255 \\
\hline Skilled agricultural and fishery workers & 61 & 39 & 33 \\
\hline Craft and related trades workers & 48 & 52 & 93 \\
\hline Plant and machine operators & 36 & 64 & 93 \\
\hline Elementary occupations & 21 & 79 & 52 \\
\hline Total $(\%)$ & 43 & 57 & 100 \\
\hline Total $(n)$ & 457 & 614 & 1,071 \\
\hline
\end{tabular}

As shown in Table 3, the wording "I am" is more common among skilled agricultural and fishery workers (61 percent), professional occupations (56 percent), and semi-professional occupations (51 percent). To respond "I work as"/"another way" is more frequent among those working in elementary, unskilled occupations (79 percent), clerks (68 percent), service, shop, market sales workers (65 percent), and plant and machine operators (64 percent). Altogether, it is more common to have a more distant approach to one's occupation: About 57 percent responded "I work as"/“another way." Such wordings are particularly common in occupations demanding less qualification. From these findings, one can assume that the propensity to adopt an occupational identity has something to do with occupational belonging.

The logistic regression analysis, shown in Table 4, shows the impact of occupational group and educational level on the tendency to use "I am" in self-presentations, as well as controlling for gender and age influences.

The first conclusion to be drawn from the regression analysis is that individuals in all major occupational groups to a higher degree use the phrase "I am" when talking about their job than individuals in elementary occupations. This focal relationship, presented in Model 1, shows statistical significance for five out of the nine occupational groups: legislators, senior officials, and managers; professionals; technicians and associate professionals; skilled agricultural and fishery workers; and craft and related trade workers. We will thus look at these occupations and how other variables affect the focal relationship.

In Model 2, where education is inserted and controlled for, we lose statistical significance for legislators, senior officials, and managers. This may be explained by this group's occupational and positional heterogeneity. The occupations in the group are engaged in planning, directing, and coordinating activities and policies in different organization types (Hansen 2001). Politicians and managers at various organizational levels are some examples. There are no educational references attached to this group's occupations and, depending on the business focus, the position holders can be recruited from various fields. The occupations here cover positions rather than occupational belonging; that is, a position, for instance a manager, refers primarily to the official hierarchical status than a specific occupation (Taylor 1968). 
Table 4: The use of "I am" in self-presentation. Logistic regression. Odds ratios. Exp. (b)

\begin{tabular}{|c|c|c|c|}
\hline & Model 1 & Model 2 & Model 3 \\
\hline \multicolumn{4}{|l|}{ OCCUPATIONAL GROUP } \\
\hline Legislators, senior officials, managers & $2.93 * *$ & 2.17 & 1.84 \\
\hline Professionals & $4.72 * * *$ & $2.86^{* *}$ & $2.62 * *$ \\
\hline Technicians and associate professionals & $3.84 * * *$ & $3.10 * *$ & $2.84 * *$ \\
\hline Clerks & 1.71 & 1.67 & 1.70 \\
\hline Service, shop, market sales workers & 2.03 & 1.88 & 1.90 \\
\hline Skilled agricultural and fishery workers & $5.73 * * *$ & $6.11 * *$ & $5.20 * * *$ \\
\hline Craft and related trades workers & $3.49 * * *$ & $3.53 * *$ & $2.84 * *$ \\
\hline Plant and machine operators & 2.10 & 2.00 & 1.70 \\
\hline Elementary occupations (reference category) & 1 & 1 & 1 \\
\hline \multicolumn{4}{|l|}{ EDUCATIONAL LEVEL } \\
\hline Elementary (ref) & Not incl. & 1 & 1 \\
\hline Vocational training, two years in high school & & $1.70 * *$ & $1.64 * *$ \\
\hline High school, 3-4 years & & 1.30 & 1.21 \\
\hline University degree, less than three years & & $1.8 * *$ & $1.83 * *$ \\
\hline University degree, three years or more & & $2.45 * * *$ & $2.54 * * *$ \\
\hline \multicolumn{4}{|l|}{ GENDER } \\
\hline $\begin{array}{l}\text { Women (ref) } \\
\text { Men }\end{array}$ & Not incl. & Not incl. & $\begin{array}{l}1 \\
1.47 * *\end{array}$ \\
\hline$A G E$ & Not incl. & Not incl. & 0.99 \\
\hline Nagelkerke & 0.059 & 0.076 & 0.086 \\
\hline Constant & $0.27 * * *$ & $0.20 * * *$ & $0.30 * *$ \\
\hline$(n)$ & 1071 & 1071 & 1071 \\
\hline
\end{tabular}

Comments: Levels of significance: $* * * p \leq 0.001,{ }^{* *} p \leq 0.01,{ }^{*} p \leq 0.05$. Dependent variable is dichotomous and measures whether the respondents said "I am" or "I work as"/, another way."

For technicians and associate professionals (semi-professions) and professionals, Model 2 shows that when education is inserted, the odds ratio decreases, but is still statistically significant. Semi-professions often require tertiary education as in a shorter university degree (less than three years) or a high school degree (Hansen 2001). Nurses, technicians, and policemen are some examples of semi-professionals found in this category. For professionals, high educational levels are requested, along with relevant knowledge and experience (Hansen 2001). In this major group, we find engineers, physicians, teachers, journalists, business administrators, etc. The drop in the odds ratio, when introducing educational level, implies a great amount of occupationally related identity shaping occurs in educational training. Both semi-professional and professional occupations require a university degree. Table 4 also shows that the likelihood of using "I am" is higher when an individual has a university degree.

As concerns education's impact on occupational identity formation, yet another result emerges in Model 2. For craft and related trade workers and skilled agricultural and fishery workers, the positive occupational identity odds ratio increases when education is inserted into the model. A possible explanation for this is that their occupational identity is based on the actual work and the work settings rather than on education. However, the variable education analysis shows that vocational training influences occupational identity. From these findings, we can conclude that for those who work in these occupational fields and lack vocational training (elementary schooling), occupational identity shaping takes place at work. Thus, those who lack a formal education are more dependent on identity shaping at work. One should also bear in mind that workers in these fields tend to demonstrate substantial occupational pride (cf. Willis 1977; Ulfsdotter Eriksson and Flisbäck 2011).

In Model 3 we control for gender and age. Table 4 shows that while age does not impact the willingness to use occupation in self-presentations, gender does. As concerns gender, we can conclude that, generally, men use the phrase "I am" more than women. This implies that men are more willing than women to relate to their work as part of a social identity. All significant odd ratios decrease when gender is inserted in the analysis. Gender as a variable that has an explanatory power of its own may be explained by the presence of a gender-related identity. 


\section{Concluding remarks}

The regression analysis confirms that among incumbents in some of the occupational groups, one's occupation still has self-presentation importance. As also shown in frequencies, skilled agricultural and fishery workers, professionals, technicians and associate professionals, and craft and related trades, workers to a higher degree relate to their occupation by using the phrase "I am" when talking about their own occupation. What unites these professions, and, conversely, distinguishes them from the others, are the different socialization forms.

Both agriculture and fishery are occupations to which many incumbents are socialized from early childhood; that is, they are "inherited". The professions and semi-professions are educational occupations that require several years of university studies, where not only pure knowledge, but also occupational cultures and norms are taught. The students are thus socialized during training. The same is valid for craft workers attending vocational education where part of the training is placed in actual practice.

The educational setting's influence on occupational identity formation is confirmed. Training to an occupation in an educational setting affects the willingness to adopt an occupational identity. The analyses show that individuals with a university degree or a vocational high school education are more likely than individuals with only elementary school education to identify with their occupation.

Age has no significant impact on whether or not an individual adopts an occupational identity. This may imply that number of years in an occupation, or in the labor market, is not sufficient for developing an occupational identity. Researchers who claim that occupational identity is an old-fashioned concept argue that due to the contemporary labor market's enhanced flexibility, people do not establish a relationship strong enough to serve as a social identity basis (Casey 1995; Sennett 1998; Isacson and Silvén 2002). The findings presented in this article contradict such claims. However, one should consider that, according to research, identity work is an "ongoing mental activity that an individual undertakes in constructing an understanding of self that is coherent, distinct and positively valued" (Alvesson et al. 2008: 15). This implies that social identity develops even if individuals change settings and thus that occupational identity is a valid concept even in unstable and flexible times.

The hypothesis discussed in the Introduction seems valid: Individuals who recognize and declare an occupational identity are engaged in a high-status occupation, are professionals and/or have a defined education, or work in an occupation with a strong cultural framing. However, previous occupational identity research shows that incumbents in low-status occupations also display positive occupational identification. Taken together, despite the new employment conditions and enhanced flexibility of modern working life, we can conclude that occupational identity is still valid for various occupations' incumbents.

\section{Acknowledgment}

Thanks to Tomas Berglund and Bengt Larsson and the anonymous reviewers for valuable comments.

\section{REFERENCES}

Alvesson, Mats, Karen L. Ashcraft and Robyn Thomas. 2008. "Identity Matters: Reflections on the Construction of Identity Scholarship in Organization Studies." Organization 15(1): 5-28.

Aneshensel, Carol S. 2002. Theory-Based Data Analysis for the Social Sciences. Thousand Oaks: Pine Forge Press.

Ashforth, Blake E. and Fred Mael. 1989. "Social Identity Theory and the Organization." The Academy of Management Review 14: 20-39.

Ashforth, Blake E. and Glen E. Kreiner. 1999. “'How can you do it?' Dirty work and the challenge of constructing a positive identity." Academy of Management Review 24: 413-434.

Becker, Howard and James W. Carper. 1956. "The Development of Identification with an Occupation." The American Journal of Sociology 61: 289-298.

Casey, Chaterine. 1995. Work, Self and Society. After Industrialism. New York: Routledge.

Doherty, Michael. 2009. "When the working day is through: the end of work as identity?" Work, Employment \& Society 23(1): 84-101.

Edling, Christoffer and Peter Hedström. 2003. Kvantitativa metoder: Grundläggande analysmetoder för samhälls- och beteendevetare. Lund: Studentlitteratur.

Elliott, Philip. 1972. The Sociology of Professions. London: Macmillan.

Ellemers, Naomi, Alexander S. Haslam, Michael J. Platow and Daan van Knippenberg. 2003. "Social Identity at Work: Developments, Debates, Direction." In A. Haslam et al. (eds.) Social Identity at Work. Developing Theory for Organizational Practice. New York: Psychology Press.

Hall, Richard H. 1969. Occupations and the Social Structure. Englewood Cliffs: Prentice-Hall. 
Hansen, Lars. 2001. Division of Labour in Post-Industrial Societies. Göteborg: Department of Sociology, Göteborg University.

Hughes, Everett C. 1971/2008. The Sociological Eye. Selected papers. New Brunswick: Transaction Books.

Isacson, Mats and Eva Silvén. 2002. "Yrken och yrkeskonstruktion i det moderna och senmoderna samhället." In L. Abrahamsson et al. (eds.) Utbildning, kompetens och arbete. Lund: Studentlitteratur.

ISCO 88 http://www.ilo.org/public/english/bureau/stat/isco/isco88/index.htm

Katz, Daniel and Robert L. Kahn. 1978. The Social Psychology of Organizations. New York: John Wiley and Sons.

Kirpal, Simone. 2004. "Researching work identities in a European context." Career Development International 9: 199-221.

Krause, Elliott A. 1971. The Sociology of Occupations. Boston: Little, Brown and Company.

Nakao, Keiko and Julia Treas. 1994. "Updating Occupational Prestige and Socioeconomic Scores: How the New Measures Measure Up.” Sociolocial Methodology 24:1-71.

Patmalnieks, Ann. 2011. "De går i föräldrarnas fotspår." Du and Jobbet 2011-01-04.

Phelan, Shannon and Elizabeth Anne Kinsella. 2009.”Occupational Identity: Engaging Socio-Cultural Perspectives." Journal of Occupational Science 16: 85-91.

SCB 2005. Statistisk årsbok. Stockholm: Statistiska centralbyrån.

Sennett, Richard. 1998. The Corrosion of Character. The Personal Consequences of Work in the New Capitalism. New York: W. W. Norton.

Soidre, Tiiu. 2004. "Unemployment risks and demands on labour-market flexibility: an analysis of attitudinal patterns in Sweden.” International Journal of Social Welfare 13: 124-133.

SSYK 96. SCB (2010) https://www.h.scb.se/amlsykl/slp/ssyk.asp

Tajfel, Henri and John Turner. 1979. “An Integrative Theory of Intergroup Conflict.” In W.G. Austin and S. Worchel (eds.) The Social psychology of Intergroup Relations. Monterey, CA: Brook/Cole.

Taylor, Lee. 1968. Occupational Sociology. New York: Oxford University Press.

Treiman, Donald J. 1977. Occupational Prestige in Comparative Perspective. New York: Wiley.

Ulfsdotter Eriksson, Ylva. 2006. Yrke, status och genus - en sociologisk studie om yrken på en segregerad arbetsmarknad. Göteborg: Department of Sociology, Göteborg University.

Ulfsdotter Eriksson, Ylva. 2012. "Work Attitudes in Low-Status Occupations: More than Instrumentalism". In B. Furåker et al. (eds.) Commitment to Work and Job Satisfaction: Studies of Work Orientations. Routledge Studies in Management, Organizations and Society. New York: Routledge.

Ulfsdotter Eriksson, Ylva and Marita Flisbäck. 2011. Yrkesstatus - Erfarenhet, identitet och erkännande. Malmö: Liber.

Walsh, Kate and Judith R. Gordon. 2008. "Creating an individual work identity." Human Resource Management Review 18: 46-61.

Weber, Max. 1978. Economy and Society. An Outline of Interpretive Sociology. Berkeley: University of California Press.

Willis, Paul. 1977. Learning to Labour. How Working Class Kids Get Working Class Jobs. Farnborough: Saxon House. 